\title{
Demanding and challenging: Men's experiences of living with a pregnant woman with pelvic girdle pain: An interview study
}

\author{
Helen Elden ${ }^{1}$, Ingela Lundgren ${ }^{1}$, Eva Robertson ${ }^{2}$ \\ 1. Institute of Health and Care Sciences, The Sahlgrenska Academy at University of Gothenburg, Sweden. 2. Faculty of \\ Professional studies, University of Nordland, Bodø, Norway.
}

Correspondence: Helen Elden. Address: Institute of Health and Care Sciences, The Sahlgrenska Academy at University of Gothenburg Box 457, 40530 Gothenburg, Sweden. Email: Helen.elden@gu.se

Received: June 5, 2014

Accepted: July 22, 2014

Online Published: July 25, 2014

DOI : $10.5430 /$ cns.v2n4p17

URL: http://dx.doi.org/10.5430/cns.v2n4p17

\section{Abstract}

Background: Pelvic girdle pain (PGP) is a universally disabling condition affecting approximately 50\% of pregnant women. Qualitative research describes how PGP leads to struggle in women's daily lives, makes them question and doubt their roles and identities as professionals and mothers, and test their (marital) relationships. The purpose of this study was to describe men's experiences of living with a pregnant woman with PGP.

Methods: Participants were men whose pregnant partners participated in a project containing both qualitative and quantitative studies in 2009 to 2011. Interviews were conducted in person $(\mathrm{n}=18)$ or by telephone $(\mathrm{n}=8)$, lasting approximately 20-50 minutes. Sixteen men were interviewed during their wive's pregnancies ( $\mathrm{M}$ age $=30$ years), eight men were re-interviewed within 12 months postpartum and two men were interviewed only postpartum (26 interviews).

Results: Three major categories emerged: having no knowledge of PGP, a period of emotional and physical strain, and merging. Pregnancy in a woman with PGP caused men to alter focus from themselves to their partners and family. They expressed worry, powerlessness, inadequacy, and a need for support. They had to adapt and cope, both demanding and challenging. However, they stressed that relationships with their older children improved, and that they and their partners had succeeded in becoming a team.

Conclusions: The findings indicated a need for greater focus from midwives and other health care providers on the psychological impact of PGP on the man/partner. This is important, not only for men but for their respective women as well, whereby men influence their partner's health.

\section{Key words}

Experience, Pregnancy, Pelvic girdle pain, Qualitative interview study

\section{I ntroduction}

Pelvic girdle pain (PGP) is a universal problem regardless of socioeconomic factors ${ }^{[1-7]}$, affecting 30 to $50 \%$ of pregnant women ${ }^{[8,9]}$. It is a musculoskeletal pain located between the posterior iliac crests and gluteal folds, and may radiate down the thigh but rarely into the lower leg ${ }^{[9]}$. The etiology is poorly understood but a combination of postural changes, the 
growing fetus, unstable pelvic joints under the influence of pregnancy hormones and changes in the centre of gravity contribute to the varying degree of pain or discomfort ${ }^{[7]}$. PGP causes dysfunction, emotional distress ${ }^{[10]}$, and reduced health-related quality of life for the pregnant woman ${ }^{[8,9,11,12]}$. Qualitative studies have shown that PGP in pregnancy causes women, struggling with daily life, to doubt their roles and identities as professionals and mothers ${ }^{[12,13]}$. It also tries their relationships ${ }^{[12,14]}$. Also, the complaint is often trivialized in healthcare ${ }^{[14,15]}$. Efficient treatments are lacking, but acupuncture and specific stabilising exercises as an adjunct to a pelvic belt, ergonomic advice and home training exercises have been shown to decrease pain and improve function ${ }^{[2,11,16]}$. PGP has been found to disappear soon after delivery but tends to recur in future pregnancies ${ }^{[7]}$.

It has been reported that most expectant fathers experience some psychological, social and/or physical changes during normal pregnancies, and that support and encouragement during pregnancy may be as important to them as to expectant mothers ${ }^{[17,18]}$. Expectant fathers' experiences of their partners' pregnancies do not seem to be as well documented as that of expectant mothers'. A study from Sweden shows that antenatal care focused on the partner's labour and childbirth while their own concerns were neglected ${ }^{[19]}$. It is known that support from men during pregnancy serves to alleviate the burden of stress and improves maternal wellbeing in healthy women ${ }^{[20,21]}$. Earlier research has concluded that whereby the condition has an impact on the affected women's relationships, investigations of how the condition of PGP was experienced by their partners may further contribute to the knowledge of this field ${ }^{[12,13]}$. However, to our knowledge, there is no study focusing on men's experiences of living with a pregnant woman suffering from PGP.

\section{Aim of the study}

This study aims to describe men’s experiences of living with a pregnant woman with PGP.

\section{Methods}

The study was conducted between May 2009 and June 2011 in Gothenburg, Sweden.

\subsection{Qualitative method}

A qualitative approach was selected as the most appropriate methodology to guide data collection and analyses for this study. Conventional qualitative content analysis ${ }^{[22-24]}$ was used inductively ${ }^{[24]}$. This method has roots in social science and communication theory. It is well-suited for analysing the multifaceted, sensitive phenomena in this study with expectant fathers' experiences of a partner with PGP, and preferable in light of the lack of previous studies dealing with the phenomenon ${ }^{[24]}$.

\subsection{I nformants}

\subsubsection{Recruitment of informants}

Swedish-speaking men were eligible for participation if they were partners to pregnant women with PGP included in a project containing both a quantitative ${ }^{[25]}$ and qualitative studies ${ }^{[12,15]}$.

\section{I nterview I (during partners pregnancy)}

All 27 women included in the referred qualitative studies ${ }^{[12,15]}$ were asked permission if HE could send an invitational letter and written information for the ongoing study to their partners. All the women complied with this. Thus, 27 men were sent written information about the study. About a week later the men were contacted by telephone by HE. Eighteen men accepted participation. They were provided further details of the study and an interview was booked. For practical reasons three men chose to be interviewed by telephone. Two men later cancelled the interview due to lack of time. Thus, a total of 16 interviews were performed (see Table 1). Those that cancelled the interview and those interviewed were asked 
if they were willing to be contacted for a new interview six to 12 months after the birth of their child. Fourteen men gave their approval while two men declined as they were to work abroad after the birth.

\section{I nterview II (six to twelve months after pregnancy)}

Fourteen men were eligible for interview II. When contacted by telephone four men declined due to lack of time. Thus, appointments for interviews were made with $10 \mathrm{men}$. Five were interviewed face-to face and five chose to be interviewed by telephone due to practical reasons (see Table 1 ).

\subsubsection{Description of informants}

The informants' varying socioeconomic groupings, age and experiences of the phenomenon increased the possibility of shedding light on the research question, from a variety of aspects (see Table 1).

Table 1. Characteristics of interviews and participants.

\begin{tabular}{lll}
\hline & $\begin{array}{l}\text { Interviewed during partners pregnancy } \\
(\mathbf{n = 1 6 )}\end{array}$ & $\begin{array}{l}\text { Interviewed within 12 months postpartum } \\
(\mathbf{n}=\mathbf{1 0})\end{array}$ \\
\hline $\begin{array}{l}\text { Informant id } \\
\text { Interview in person }\end{array}$ & 13 -4; 6-10; 12-18 & $5,7,9-12 ; 14-17$ \\
Online interview & $3(19)$ & $5(50)$ \\
Interview & $5(50)$ \\
length, range & $20-60$ & $20-50$ \\
length, minutes & 34 & 34 \\
Race/Ethnicity & & \\
Caucasian & $16(100)$ & $10(59)$ \\
Age & & $28-41$ \\
Range, years & $28-40$ & $34.2(2.7)$ \\
Mean, years (SD) & $33.3(2.4)$ & $2(20)$ \\
Education & & $8(80)$ \\
High school & $4(25)$ & \\
University & $12(75)$ & $10(100)$ \\
Marital Status & & \\
Married/cohabiting & $16(100)$ & $4(40)$ \\
Parental status & $7(44)$ & $5(50)$ \\
First-time father & $7(44)$ & $1(10)$ \\
Second-time father & $2(12)$ & \\
Third-time father & &
\end{tabular}

Figures are n (\%) if not stated otherwise

\subsection{Data collection}

The first author (HE) conducted interviews by phone or in person based on participant preference and location of residence. An open-ended question was used: “Can you tell me about your experiences of living with a pregnant woman with PGP”? Follow-up questions were asked based on the respondent's answers ${ }^{[26]}$. The aim was to be open and flexible in order to follow the men's stories and thoughts. Thus, the men were given the opportunity to talk about matters difficult to discuss with others ${ }^{[27]}$. Interviews were audiotaped and transcribed verbatim and de-identified before the analysis. 
Ethical approval was obtained from the regional ethics committee (ref: 703-09) and informed consent was obtained from each participant prior to participation. Participants were informed that all data would be de-intified during transcription of recording to protect identities.

\subsection{Data analysis}

For data analysis we followed the description by Granheim and Lundman ${ }^{[22]}$. Interviews were transcribed verbatim and an analysis was conducted using $\mathrm{NVivo}^{8}$ (www. qsrinternational.com/). At first, the texts were read through repeatedly to obtain a composite perspective. They were then divided into units of meaning, i.e. phrases describing the men's experiences of living with a pregnant woman with PGP. In the next step two of the authors (HE and ER) both independently and together, gave the units of meanings a code consisting of either a single word or sentence. Examples of codes were: 'knowledge of PGP', 'relationships', 'emotions' and 'strategies'. The codes were discussed, and some diverging codes were re-coded until consensus was reached. Next, similar codes were grouped into sub-categories and categories, which was checked for reliability in a process of moving back and forth in the data ${ }^{[22,24]}$. To facilitate the transferability of this study (included in trustworthiness), a clear description of the context, selection and characteristics of participants, data collection, process of analysis and appropriate quotations from the interviews are presented ${ }^{[22,27]}$.

\section{Results}

Three categories emerged from the analysis describing the men's experiences of living with a pregnant woman with PGP; 1) lacking knowledge of PGP, 2) a period of emotional and physical strain and, 3) merging (see Table 2).

Table 2. Categorical system describing men's experiences of living with a pregnant woman with PGP

\begin{tabular}{ll}
\hline Sub-categories & Categories \\
\hline $\begin{array}{l}\text { Need of knowledge } \\
\text { Complaints difficult to understand }\end{array}$ & Lacking knowledge of PGP \\
Lack of space (for oneself) & \\
PGP limits daily life & A period of emotional and physical strain \\
Sadly missing a normal sex life & \\
Feeling bad because she feels bad & \\
"Grin and bear it" & Merging \\
Becoming a team & \\
Needing and feeling supported & \\
Taking a stance on future pregnancies &
\end{tabular}

\subsection{Lacking knowledge of PGP}

\subsubsection{Need for knowledge}

The men lacked information and knowledge of what PGP was, and the implications of the woman gaining information from the midwife at the Antenatal Care Centre (ANC). They spoke of worrying about not knowing whether PGP could injure the fetus or not and not knowing what type of pain could be dangerous during pregnancy.

When she said she was in great pain, I said I thought we that we should seek help at the maternity ward (IP 10).

They sought tips on how they could ease PGP. One man reflected: I believe we men generally find that very important; to be able to do something that will make things better (IP 3). The men also said that they gained no information of PGP from other men. Some men said they had looked for information about PGP on the Internet. They had found both good and poor information but concluded that everyone should be careful about what they read in blogs. 
You have to avoid those blogs that only present the worst cases (IP 8).

\subsubsection{Complaints hard to understand}

Most men said that PGP was totally unknown to them before their partners suffered from it. It appeared abstract and difficult to understand. The men felt completely unprepared for the symptoms, which meant helping with basic things such as turning over in bed and getting in and out of the bath.

The concepts of pelvic joint instability, pelvic floor pain and such things were completely new and unknown to me (IP 16).

\subsubsection{Being unprepared for the early onset of PGP}

Men who had already experienced a pregnancy in which their woman had PGP were still not prepared for the fact that PGP could start even before visible signs of pregnancy. They also related how symptoms affected their lives even more during the second pregnancy with PGP since there was also a young child to care for. One man described the time of PGP as a state of continuing emergency.

Then I thought if it’s like this now I'll have to drive her around in a wheelbarrow the last two month (IP15).

\subsection{A period of personal physical and emotional strain}

\subsubsection{Missing time alone}

The men told of how they were used to being able to plan time for themselves but were now frustrated because they could no longer do so. They missed moments of peace and quiet for themselves after coming home from work. If they did manage to get a moment to relax they then had the strength to do everything that was needed at home.

Yes, I just want to be alone, just need a few minutes to myself, to crawl into my own little cocoon (IP 5).

Some fathers of young children told how they tried to get some time alone at lunch or later in the evening when the children were asleep. Time to themselves could be used to work in the garden, meet with friends or get some exercise.

It's a small way of catching your breath...a tiny bit of space (IP 4).

The men said that they had to opt out of certain things and prioritize others to be able to handle life with PGP. One man said that when he told his male friends he had to prioritize his family they were unsympathetic. This made him sad and disappointed, but even if he missed his friends he was pleased with the choice he had made.

I feel they should try to understand instead...they were against me and said I couldn’t give up so much of my life (IP 17).

\subsubsection{PGP limits life}

The men told of how PGP dampened their lives since their women were not up to a social life. If there was to be any social activity the men had to take the initiative. They did so occasionally but often chose a quiet evening at home. The men also described how they missed doing things alone as a couple. Going swimming usually went well and was highly appreciated. But the women could not, for the most part, participate in any activities whatsoever. They could only sit, but not for long, as that was also painful in the end.

...things we used to do, like skating or walking over to the park over there, have now become unthinkable. It's a one kilometre walk but it might as well be to the moon (IP 16). 


\subsubsection{Sadly miss a normal sex life}

The men told of how they lacked intimacy and sex. Some said that the lack of sex was not just due to PGP but to the intensity of life in general. It was difficult to both manage work and care for the household and children, leaving little time for each other.

Well, there's no denying that one undoubtedly misses sex, but this too will pass. You have to see it that way, and having another child is wonderful (IP 14).

\subsubsection{Feeling bad because she feels bad}

The men expressed how their own wellbeing was highly dependent on the wellbeing of their spouses, and that concern for their woman's health affected them. Some stated that there was no room for them to feel bad, that it wasn't permitted, since the woman was going through the worst of it and carrying a child as well. It seemed that expectancy was solely related to worry and anxiety, and that all that was positive fell away amidst all the problems. A man that was interviewed after the delivery told how he was near a state of depression and had gotten help from the midwife to get some care. He felt that family counselling saved his relationship. The men also spoke of feelings of inadequacy and guilt of not being able to do anything about their woman's PGP.

Perhaps one feels poorly although it may be masked and experienced as guilt. It gets like that but, hey, at least you can walk; why then aren’t you happy, you're expecting a child! (IP 17)

Several men spoke of how important it was to seek professional help and that it was available. Some men expressed concern for the approaching economic responsibility. At the same time they were pleased that their woman could be on sick leave and rest, although sick leave implied lower income, which they pointed out did not exactly help the situation.

\subsection{To grow together}

\subsubsection{Bite the bullet, adapt and serve}

The men talked about the importance of being proactive. One man said that if he did not ease his wife's burden he would just be making things worse. She would then be in such pain that she became completely bed-ridden and his burden even greater. They spoke of having to tell the women to take it slow and reminded them that they would have more pain if they failed to do so. They tried to encourage their women to lower their demands on household chores but that it was hard to get them to listen. They felt the women had difficulty accepting not being able to care for the home as before. Several men reflected that it was just as well that the women got used to slowing down and lowered their demands on themselves since it would be necessary when the new baby arrived. Those men with wives on sick leave who rested during the day became bored and longed for their husband's company and stimulation when they came home from work. The men were, however, exhausted and tired of socializing and only wanted to be "left in peace”. They felt it tiresome to be so "out of synch" with their mates.

She's extremely sociable when I come home since she hasn't gotten it out of her system during the day, but I just want some peace and quiet to watch TV. I find it tiresome that we're not on the same level and that she's so bored (IP 1).

The increased workload at home as a consequence of the woman's PGP was experienced as particularly burdensome by those men with small children. Some told how the increased burden gave rise to feelings of frustration and irritation that could be taken out on the spouse.

Exactly, I believe that all relationships...become inflamed after the first child... that you don't know what to do, and if she's feeling that bad it naturally affects the relationship (IP 8). 
The men pointed out how they thought it was good to know that PGP was but a temporary condition that would gradually end, and nothing to argue about. One man said: "It's just to 'bite the bullet', get through it... You have no choice in the matter. It's got to be done and I think, it will soon pass” (IP 3).

The men said that PGP influenced and changed their daily lives, and that they were forced to take greater responsibility for the home, family and social network than previously. The men said that the biggest difference was that before PGP they shared the chores. Now they had to help the woman with just about everything, and take complete responsibility for some things.

You have to do so much it wears you out...I have to admit it’s been a tough time (IP 1).

Other men mentioned that it was obvious that everyday life would change during pregnancy. That it went without saying that they would "be there 100\%" during the pregnancy. They would have done that even if the women did not suffer from PGP.

It's like I said that I don't only take consideration to the pain...but that she is in the late stages of pregnancy and that moving about is more difficult...(IP 6).

\subsubsection{Becoming a team}

Men told of how PGP caused them begin working along with their wives in a new way; that they became a team. First time fathers thought it particularly positive, and sad that it made them better prepared for the toddler years to come. After delivery the men spoke of how their altered roles during pregnancy improved their relationships to their partners. They had gained greater mutual respect, while the men gained insight into the implications of caring for the home and family, creating a better work flow than previously.

It happens there somewhere; I believe is some form of merging, and it remains to be seen whether one gets through that first period with small children. Many have shown that this is the toughest phase, so I believe you really have to struggle hard. But if you get through it, then it can be really, really good (IP 8).

The men commented that a positive effect of the woman's suffering PGP during pregnancy was that they gained a stronger bond with their older children. One man said: I have gotten closer to him, which is good (IP 8).

\subsubsection{Needing and feeling support}

Those men that had joined the women at the ANC at previous pregnancies and knew the midwife experienced a feeling of security. One of the men indicated that family counselling as recommended was very supportive. But the men also told of doctors and midwives that increased their concerns through examples of PGP leading to permanent handicap. The men emphasized the importance of good professional care and experienced a feeling of security if they felt their partner received it.

It feels good for me as well and can relax more easily. Don't know if its the right word but I also feel more secure; knowing she's in competent hands (IP 4).

The men told how it was easier for them to understand how PGP conveyed considerable difficulties in making a decision on sick leave. Disapproval by the Social Insurance physician was a cause for concern. The men felt it valuable to have support but at the same time wanted to handle things on their own. However, they paradoxically expressed that actually all help they could get was good help.

I feel sorry for those with no one close since it makes things so much easier; to have someone you know you can call if needed (IP 14). 


\subsubsection{Taking a stand on future pregnancies}

At the interviews both during and after the pregnancy most of the men said they had not as yet discussed future pregnancies or children with their partners, and did not want to take a stance in either direction:

I haven't said I want more children, but if it happens it happens. That's all there is to it. But, I sympathise with her, to go through this again, is not really worth it, I was about to say; she's had it tough, plain and simple.../with pain and pelvic instability. So it would be too tough (IP 14).

Another man felt that if they were to have another child she would surely feel as bad, but he would be more prepared for it, which would make a big difference in his experience of the pregnancy.

We would then probably long more for the child together. And perhaps I wouldn't be as worried when she has pain since now I know what it is and be more active knowing what to do (IP 17).

\section{Discussion}

To our knowledge, this is the first study describing men's experiences of living with a pregnant woman with PGP.

\subsection{Study method}

The results of this study are based on data collected from 16 interviews with men during their partner's pregnancy, and 10 interviews six to 12 months after pregnancy. The reason for conducting two interviews with the same participants was to get a description of living with a pregnant woman with PGP both during and after pregnancy.

The strengths of the study include the fact that interviews were all conducted, transcribed and analysed by the same person, which is considered important in qualitative research ${ }^{[22]}$. Also, the extra attention which the interviews implied could have had a positive effect on the result, since the men were given the opportunity to talk about matters of importance to them ${ }^{[22]}$. Another strength is that researcher IL acted as an independent analyst reviewing data and confirming subcategories and main categories.

This study had, however, several limitations. We tried to find men with varying social backgrounds but men with higher socioeconomic backgrounds were in the majority, which must be considered a limitation, and that all their spouses had recovered from PGP at the time of the interview after pregnancy. As most women with PGP during pregnancy recover within 3 months after delivery ${ }^{[7,28]}$ it was not unexpected that so was the case even with these women. The majority of informants were 30 to 40 years of age, white middle class, cohabitating with the woman, and had a university education, a pattern which generally conforms with study populations in other studies of the father's role during pregnancy ${ }^{[17,29,30]}$.

Another weakness was that not all informants were interviewed in person. The motivation for offering telephone interviews, considered more practical, was to prevent drop-outs. A weakness of this strategy may be that those interviewed by telephone did not have the same opportunity to express as deep thoughts as those interviewed in person. Nevertheless, the telephone interviews were just as long as the face-to-face interviews, indicating that this was not the case.

Moreover, informant dropout after pregnancy may have influenced findings. However, in the interviews during pregnancy many subsequent fathers spoke of their experiences of the phenomenon during earlier pregnancies. Furthermore, the dropout rate was due to 'a shortage of time', which is consistent with the increased time pressures experienced postpartum, noted in other studies ${ }^{[31]}$. Even if not all men could be interviewed post-partum we decided to analyse all interviews anyway. 
As for all qualitative research the findings must be interpreted in relation to their context when transferred to other contexts ${ }^{[22]}$. However, the fact that the findings are contextual does not imply a lack of meaning in other contexts. They must, however, be transferred and interpreted in relation to other contexts. Therefore, the extent of transferability of the results of this qualitative study to other settings and populations depends on cultural and traditional similarities or differences, and should be done with caution.

\subsection{Discussion of the results}

The main findings of this study is that men living with a partner with PGP during pregnancy lacked knowledge of PGP; had to assume greater responsibility for home care and family, which implied an altered focus from themselves to their partner and family. This was described as a period of emotional and physical strain, both demanding and challenging.

The results showed that the greatest difference between being a partner to a woman with an uncomplicated pregnancy and a woman with PGP was that besides the normal adjustment to awaiting a child and preparing for parenthood was an increased burden on several levels. They expressed this as 'feeling bad because she feels bad' and that PGP 'limited life'. The often handicapping condition caused dependence on help with normal functions such as moving or turning over in bed. The men who experienced pregnancies where the women had PGP described being forced to take over the woman's share of household chores, shopping, and caring for the children. They spoke of having to support and calm the women burdened by increased worry due to PGP. This is in agreement with earlier studies describing how pregnant women with PGP were concerned by their bodies not functioning as usual ${ }^{[13,15]}$; that they felt down and frustrated for not fully functioning as partners, mothers, and professionals ${ }^{[32]}$, and bore an increased worry of not being capable of the approaching birth ${ }^{[15]}$. The men also described how they 'sadly missed a normal sex life' due to PGP, which has also been expressed in interviews with women with PGP ${ }^{[12]}$. Moreover, unsatisfying sexual life during pregnancy due to PGP has also been reported in two questionnaire-based surveys of 1298 women ${ }^{[29,33]}$. Midwives/caregivers should provide information and support about the influences of pregnancy on daily life and sexual activity ${ }^{[34-36]}$. It is important to point out the significance of specific information about PGP's effects on sex life. Information about short-term aggravation after having sex is particularly important ${ }^{[12]}$. Couples in need of such information should be offered supportive sexual counselling on either a one-to-one basis or as couples during pregnancy. Adequate support may protect the couple from further strains on the relationship during the neonatal and early childhood period, a period with a relatively high level of separations among parents ${ }^{[37]}$. Lack of knowledge and information on PGP was a considerable contributing factor to the men's worry. The men spoke of a lack of information about PGP from midwives and doctors at ANC. Not knowing that PGP was harmless to both the mother and child led to unnecessary worries; and not knowing how to support their women made them feel powerless. Lack of sufficient information at ANC is in agreement with earlier research of antenatal care during uncomplicated pregnancies $^{[18,31,34,38,39]}$ and of described experiences from women with PGP ${ }^{[15]}$. Lack of information of PGP from ANC made them turn to the Internet, a common source of pregnancy and childbirth information ${ }^{[40]}$. However, they found no accurate information about PGP there. Actually, they warned other men as they thought that the information on the Internet more likely frightened than calmed them. Similar experiences have been described by women with PGP ${ }^{[41]}$.

Pregnancy as a period of overwhelming emotions in which expectant fathers go through physiological, physical and social changes and psychological distress have been described by other researchers ${ }^{[42-44]}$, although not in relation to PGP. The increased responsibility and workload due to PGP together with a lack of knowledge and control over the process most likely enhanced men's anxiety, frustration and irritation. One of the men spoke of signs of depression. It seems important to note these emotions as there is data indicating that feelings of isolation, sadness, fear and anxiety are central to men who develop depression ${ }^{[45]}$, and that the paternal depression rate might be increased during pregnancy as is seen in mothers ${ }^{[46]}$. Shortcomings in antenatal care have also been reported as leading men to avoid asking questions about things they are unsure of ${ }^{[39,43]}$. Our findings underscore results from studies that indicate that women are dissatisfied with the emotional aspect of antenatal care ${ }^{[47]}$ as well as the midwives' concerns that the expectant father is often left out during prenatal cares ${ }^{[19]}$. It seems even more serious with such shortcomings when pregnancy is complicated by a disabling condition such as PGP. Professionals working in antenatal care and services should provide information about possible emotional and 
psychological changes during the process of becoming parents to enable more realistic expectations, as previously discussed ${ }^{[48]}$.

Men experience comparatively greater social pressure than women to endorse gendered societal prejudices such as the strongly emphasised beliefs that men are independent, self-reliant, strong, robust and tough ${ }^{[49]}$. The men in our study emphasized that the most important issues in prenatal care were the woman's physical and emotional well-being. They experienced considerable security if their partner received good professional care from the midwife. The men also spoke of how important it was to dare to seek professional help and that it was available. One man described how family counseling saved their relationship. It has been suggested that training of health care providers is of great importance to stress the need to encourage and welcome fathers in the prenatal process, as they are in a key position to be influential to the mother's health behaviour ${ }^{[21,50]}$. It has also been shown that attention and emotional support during pregnancy gives men better physical and emotional health and made them better able to maintain good relationships with their spouses than those with no support ${ }^{[51]}$, which in turn benefitted the women, and the infants ${ }^{[31,38]}$. Adequate support is probably of even greater importance when the woman has a disabling condition such as PGP. Moreover, it may protect the couple from further strains on the relationship during the neonatal and early childhood period, a period with a relatively high level of separations among parents ${ }^{[37]}$. This study stresses a need for better support for these men, which requires that more resources must be allotted to ANC. Such preventive work could perhaps avert some unnecessary worries and stress. Perceived and received social support have also been shown to moderate the effects of a variety of stressors on health and marital relationships ${ }^{[52,53]}$. However, pregnant partners, extended family, and friends are not always able to provide the level of social support an expectant father needs ${ }^{[51,53,54]}$.

Some men in this study stated that they questioned future pregnancies because they did not want to subject their woman to the risk of PGP again. These findings are consistent with results from studies describing how women with PGP do not look forward to further pregnancies ${ }^{[9,12]}$. It seems necessary that the midwife provide the couple with information that even if the risk for PGP increases in a future pregnancy, the risk is not absolute and most women will recover rapidly after pregnancy ${ }^{[7,9]}$. The men also described some positive experiences of the woman having PGP. They said that the relationship with the older children and their partner improved and that they became a team, which they thought should facilitate the toddler stage. Our results should be considered a contribution to the body of knowledge on subjective experience of PGP during pregnancy. It may contribute to an increased understanding of this common disabling condition during pregnancy and thus improve ANC. However, more research in this area is warranted.

\section{Conclusions}

The findings of this study describe that a pregnancy with a woman with PGP made some men take greater responsibility for home care and family, and change their focus from themselves to their partners and families. They expressed feeling worried, powerless and insufficient, and that they had to adapt and cope in all ways, which was both demanding and challenging. They desired readily available professional support and concrete advice. These findings indicate a need for increased awareness and focus from midwives and other health care providers on the impact of PGP on daily life situations and relationships for the men, as well as the impact of gender aspects. This is important, not only for the men but also because it is known that fathers influence the mother's health.

\section{Acknowledgement}

We want to express our appreciation to all the men for their contributions to this study. We would also like to thank language editor and translator Mark Rosenfeld for significant revisions to the manuscript.

\section{Source(s) of support}

This study was supported by research grants from The Health \& Medical Care Committee of the Regional Executive Board, Region Vastra Götaland (Sweden), grant number: VGFOUREG-155171. 


\section{Contributors}

All authors participated in the design and interpretation of the results and drafting of the article. HE contributed to recruitment procedures, data collection, data analysis and management of the trial. IL and ERO contributed to analysis of the data.

\section{References}

[1] Bastiaenen C, de Bie R, Essed G. Pregnancy-related pelvic girdle pain. Acta Obstet Gynecol Scand. 2007; 86: 1277-1278; Bastiaenen C, de Bie R, Essed G. Pregnancy-related pelvic girdle pain. http://dx.doi.org/10.1080/00016340701659163

[2] Elden H, Ladfors L, Olsen MF, Ostgaard HC, Hagberg H. Effects of acupuncture and stabilising exercises as adjunct to standard treatment in pregnant women with pelvic girdle pain: randomised single blind controlled trial. BMJ. 2005 Apr 2; 330(7494): 761-764. Epub 2005 Mar 18. http://dx.doi.org/10.1136/bmj.38397.507014.E0

[3] Keriakos R, Bhatta SR, Morris F, Mason S, Buckley S. Pelvic girdle pain during pregnancy and puerperium. Journal of obstetrics and gynaecology: the journal of the Institute of Obstetrics and Gynaecology. 2011; 31: 572-580. PMid:21973126 http://dx.doi.org/10.3109/01443615.2011.598970

[4] Bjorklund K, Bergstrom S. Is pelvic pain in pregnancy a welfare complaint? Acta Obstet Gynecol Scand. 2000; 79: 24-30. http://dx.doi.org/10.1080/j.1600-0412.2000.079001024.x

[5] Mukkannavar P, Desai BR, Mohanty U, Kulkarni S, Parvatikar V, Daiwajna S. Pelvic girdle pain in Indian postpartum women: a cross-sectional study. Physiother Theory Pract. 2014 Feb; 30(2): 123-130. http://dx.doi.org/10.3109/09593985.2013.816399

[6] Pierce H, Homer CS, Dahlen HG, King J. Pregnancy-related lumbopelvic pain: listening to Australian women. Nurs Res Pract. 2012; 387428. http://dx.doi.org/10.1155/2012/387428

[7] Vermani E, Mittal R, Weeks A. Pelvic girdle pain and low back pain in pregnancy: a review. Pain Pract. 2010 Jan-Feb; 10(1): 60-71. http://dx.doi.org/10.1111/j.1533-2500.2009.00327.x

[8] Gutke A, Ostgaard HC, Oberg B. Pelvic girdle pain and lumbar pain in pregnancy: a cohort study of the consequences in terms of health and functioning. Spine (Phila Pa 1976). 2006; 31: E149-155.

[9] Vleeming A, Albert HB, Ostgaard HC, Sturesson B, Stuge B. European guidelines for the diagnosis and treatment of pelvic girdle pain. Eur Spine J. 2008 Jun; 17(6): 794-819. http://dx.doi.org/10.1007/s00586-008-0602-4

[10] Bjelland EK, Stuge B, Engdahl B, Eberhard-Gran M. The effect of emotional distress on persistent pelvic girdle pain after delivery: a longitudinal population study. BJOG. 2013; 120: 32-40. http://dx.doi.org/10.1111/1471-0528.12029

[11] Elden H, Fagevik-Olsen M, Ostgaard HC, Stener-Victorin E, Hagberg H. Acupuncture as an adjunct to standard treatment for pelvic girdle pain in pregnant women: randomised double-blinded controlled trial comparing acupuncture with non-penetrating sham acupuncture. BJOG. 2008; 115: 1655-1668. PMid:18947338 http://dx.doi.org/10.1111/j.1471-0528.2008.01904.x

[12] Elden H, Lundgren I, Robertson E. Life's pregnant pause of pain: Pregnant women's experiences of pelvic girdle pain related to daily life: A Swedish interview study. Sex Reprod Healthc. 2013 Mar; 4(1): 29-34. http://dx.doi.org/10.1016/j.srhc.2012.11.003

[13] Persson M, Winkvist A, Dahlgren L, Mogren I. "Struggling with daily life and enduring pain”: a qualitative study of the experiences of pregnant women living with pelvic girdle pain. BMC Pregnancy Childbirth. 2013 May 13; 13: 111. PMid:23668823. http://dx.doi.org/10.1186/1471-2393-13-111

[14] Wellock K, Crichton M. Pain, disability and symphysis pubis dysfunction: women talking. Evidence Based Midwifery. 2008; 6: 9-17.

[15] Elden H, Lundgren I, Robertson E. The pelvic ring of pain: Pregnant women's experiences of severe pelvic girdle pain: An interview study. Clinical Nursing Studies. 2014; 2: 2. http://dx.doi.org/10.5430/cns.v2n2p30

[16] Pennick V, Liddle SD. Interventions for preventing and treating pelvic and back pain in pregnancy. Cochrane Database Syst Rev. 2013 Aug 1; 8: CD001139. PMid:23904227

[17] Premberg A, Carlsson G, Hellstrom AL, Berg M. First-time fathers' experiences of childbirth--a phenomenological study. Midwifery. 2011; 27: 848-853. PMid:20956030 http://dx.doi.org/10.1016/j.midw.2010.09.002

[18] Finnbogadottir H, Crang Svalenius E, Persson EK. Expectant first-time fathers' experiences of pregnancy. Midwifery.2003; 19: 96-105. http://dx.doi.org/10.1016/S0266-6138(03)00003-2

[19] Premberg A, Lundgren I. Father's experiences of Childbirth education. Journal of Perinatal Education. 2006; 15: 21-28. http://dx.doi.org/10.1624/105812406X107780

[20] Ghosh J, Wilhelm M, Dunkel-Schetter C, Lombard I, Ritz B. Paternal support and preterm birth, and the moderation of effects of chronic stress: a study in Los Angeles County mothers. Arch Womens Ment Health. 2010: 327-338.

http://dx.doi.org/10.1007/s00737-009-0135-9

Published by Sciedu Press 
[21] Alio A, Lewis C, Scarborough K, Harris KF, Fiscella KA. Community perspective on the role of fathers during pregnancy: a qualitative study. BMC Pregnancy Childbirth. 2013; 13: 60. http://dx.doi.org/10. 1186/1471-2393-13-60

[22] Graneheim U, Lundman B. Qualitative content analysis in nursing research: Concepts, procedures and measures to achieve trustworthiness. Nurse Educ Today. 2004 Feb; 24(2): 105-112. http://dx.doi.org/10.1016/j.nedt.2003.10.001

[23] Hsieh H, Shannon S. Three approaches to qualitative content analysis. Qualitative health research 2005; 15: $1277-1288$. PMid:16204405 http://dx.doi.org/10.1177/1049732305276687

[24] Elo S, Kyngas H. The qualitative content analysis process. J Adv Nurs. 2008 Apr; 62(1): 107-15. PMid:18352969 http://dx.doi.org/10.1111/j.1365-2648.2007.04569.x

[25] Elden H, Östgaard HC, Glantz A, Marciniak P, Linnér AC, Olsén MF. Effects of craniosacral therapy as adjunct to standard treatment for pelvic girdle pain in pregnant women: a multicenter, single blind, randomized controlled trial. Acta Obstet Gynecol Scand. 2013 Jul; 92(7): 775-782. http://dx.doi.org/10.1111/aogs.12096

[26] Kvale S, Brinkmann S. Den kvalitativa forskningsintervjun. Lund: Studentlitteratur. 2009.

[27] Dahlberg K, Dahlberg H, Nyström M. Reflective life world research Lund: Studentlitteratur; 2008.

[28] Elden H, Hagberg H, Olsen MF, Ladfors L, Ostgaard HC. Regression of pelvic girdle pain after delivery: follow-up of a randomised single blind controlled trial with different treatment modalities. Acta Obstet Gynecol Scand. 2008; 87(2): 201-208. http://dx.doi.org/10.1080/00016340701823959

[29] Klinth R, Johansson T. Nya svenska fader Umeå: Boréa; 2010.

[30] Fletcher R, Vimpani G, Russell G, Sibbritt D. Psychosocial assessment of expectant fathers. Arch Womens Ment Health. 2008; 11: 27-32. http://dx.doi.org/10. 007/s00737-008-0211-6

[31] Buist A, Morse C, Durkin S. Men's adjustment to fatherhood: implications for obstetric health care. J Obstet Gynecol

[32] Alstveit M, Severinsson E, Karlsen B. Living on the edge of being overstretched-a Norwegian qualitative study of employed pregnant women. Health Care for Women International 2011;31: 533-551. http://dx.doi.org/10.1080/07399331003611459

[33] Hansen A, Jensen D, Wormslev M, Minck H, Johansen S, et al. Symptom-giving pelvic girdle relaxation in pregnancy. II: Symptoms and clinical signs. Acta Obstet Gynecol Scand. 1999 Feb; 78: 111-115.

http://dx.doi.org/10.1034/j.1600-0412.1999.780207.x

[34] Olsson A, Robertson E, Bjorklund A, Nissen E. Fatherhood in focus, sexual activity can wait: new fathers' experience about sexual life after childbirth. Scand J Caring Sci. 2010: 716-725. PMid:20409069

[35] Williamson M, McVeigh C, Baafi M. An Australian perspective of fatherhood and sexuality. Midwifery. 2008; 99-107. http://dx.doi.org/10.1016/j.midw.2006.07.010

[36] Byrd J, Hyde J, DeLamater J, Plant E. Sexuality during pregnancy and the year postpartum. J Fam Pract. 1998; Oct: 305-308. PMid:9789517.

[37] Hansson M, Ahlborg T. Quality of the intimate and sexual relationship in first-time parents - a longitudinal study. Sex Reprod Healthc 2012; 3: 21-29. PMid:22325798.

[38] Barclay L, Donovan J, Genovese A. Men's experiences during their partner's first pregnancy: a grounded theory analysis. Australian Journal of Advanced Nursing. 1996; 13: 12-24. PMid:8717683.

[39] Steen M, Downe S, Bamford N, Edozien L. Not-patient and not-visitor: a metasynthesis fathers' encounters with pregnancy, birth and maternity care. Midwifery. 2012; 28:4:362-371. http://dx.doi.org/10.1016/j.midw.2011.06.009

[40] Johansson M, Rubertsson C, Radestad I, Hildingsson I. The Internet: one important source for pregnancy and childbirth information among prospective fathers. JMH. 2010 October: 249-258. http://dx.doi.org/ 10.1016/j.jomh.2010.04.004

[41] Haukeland-Fredriksen E, Moland K, Sundby J. Listen to your body. A qualitative text analysis of internet discussions related to pregnancy health and pelvic girdle pain in pregnancy. Patient Education and Counseling. 2008; 73(2): 294-299.

[42] Asenhed L, Kilstam S, Alehagen S, Baggens C. Becoming a father is an emotional roller coaster - an analysis of first-time fathers' blogs.journal of Clinical Nursing. 2013; 11: March.

[43] Boyce P, Condon J, Barton J, Corkindale C. First-Time Fathers' Study: psychological distress in expectant fathers during pregnancy. Aust N Z J Psychiatry. 2007; 41: 718-725. http://dx.doi.org/10.1080/00048670701517959

[44] Genesoni L, Tallandini M. Mens psychological transition to father- hood: an analysis of the literature, 1989-2008. Birth. 2009; 36: 305-317. PMid:20002423http://dx.doi.org/10.1111/j.1523-536X.2009.00358.x

[45] Emslie C, Ridge D, Ziebland S. Men’ accounts of depression: reconstructing or resisting hegemonic masculinity? Soc Sci Med. 2006; 62: 2246-2257. http://dx.doi.org/10. 1016/j.socscimed.2005.10.017

[46] Gawlik S, Müller M, Hoffmann L, Dienes A, Wallwiener M, Sohn C, et.al. Prevalence of parternal perinatal depressiveness and its link to partnership satisfaction and birth concerns. Arch Womens Ment Health. 2014: 19-25.

http://dx.doi.org/10.1007/s00737-013-0377-4 
[47] Hildingsson I, Radestad I. Swedish women's satisfaction with medical and emotional aspects of antenatal care. J Adv Nurs. 2005; 52(3): 239-249. http://dx.doi.org/ 10.1111/j.1365-2648.2005.03584.x

[48] Chin R, Daiches A, Hall P. A qualitative exploration of first-time fathers' experiences of becoming a father. Community Practitioner. 2011: 19-23. PMid:21941706.

[49] Garcia-Calvente Mdel M, Hidalgo-Ruzzante N, Del Rio-Lozano M, Marcos-Marcos J, Martinez-Morante E, et al. Exhausted women, tough men: a qualitative study on gender differences in health, vulnerability and coping with illness in Spain. Sociol Health Illn. 2012;34. http://dx.doi.org/10.1111/j.1467-9566.2011.01440.x

[50] Tweheyo R, Konde-Lule J, Tumwesigye N, Sekandi J. Tweheyo R, Konde-Lule J, Tumwesigye NM, Sekandi JN. Male partner attendance of skilled antenatal care in peri-urban Gulu district, Northern Uganda. BMC Pregnancy Childbirth. 2010 : 10. http://dx.doi.org/ 10.1186/1471-2393-10-53

[51] Belsky J, Rovine M. Social-network contact, family support, and the transition to parenthood. Journal of Marriage and the Family. 1984: 455-462. http://dx.doi.org/10.2307/352477

[52] Callaghan P, Morrissey J. Social support and health: A review. Journal of Advanced Nursing. 1993; 203-210. PMid:8436711http://dx.doi.org/10.1046/j.1365-2648.1993.18020203.x

[53] Mercer R, Ferketich S, DeJoseph J. Predictors of partner relationships during pregnancy and infancy. Research in Nursing \& Health. 1993; 2: 45-46. http://dx.doi.org/10.1002/nur.4770160107

[54] Wandersman L, Wandersman A, Kahn S. Social support in the transition to parenthood. Journal of Community Psychology. Journal of Community Psychology. 1980; 332-342.

http://dx.doi.org/10.1002/1520-6629(198010)8:4<332::AID-JCOP2290080407>3.0.CO;2-H 